\title{
Retroperitoneal Lymphoma
}

National Cancer Institute

\section{Source}

National Cancer Institute. Retroperitoneal Lymphoma. NCI Thesaurus. Code C7353.

A lymphoma involving the retroperitoneal area. 